\title{
Penerapan Algoritma C45 Untuk Penilaian Karyawan Pada Restoran Cepat Saji
}

\author{
Harry Dhika, Fitriana Destiawati \\ Jurusan Informatika, FTMIPA \\ Universitas Indraprasta PGRI \\ J1. Nangka No. 58A, Jakarta \\ dhikatr@yahoo.com \\ honeyzone86@gmail.com
}

\begin{abstract}
Abstrak-Kajian dilakukan pada restoran cepat saji untuk mengetahui atau memberikan nilai pada karyawannya sehingga diperoleh kesimpulan bahwa karyawan tersebut memberikan point yang baik, sangat baik dan memprediksi kurang baik. Karyawan merupakan salah satu aset yang dimiliki oleh perusahaan dalam hal ini restoran cepat saji, melihat dan menjaga kualitas dari karyawan tentunya merupakan salah satu faktor penentu keberlangsungan restoran cepat saji, untuk itu pentingnya dilakukan kajian terhadap karyawan guna menjaga dan meningkatkan kualitas restoran cepat saji. Memberikan reword kepada karwayan dengan mengkaji terlebih dahulu mepupakan apresiasi yang pantas diterima bagi aset perusahaan yakni karyawan. Metode kajian menggunakan konsep data mining menggunakan algoritma $\mathrm{C45}$ yang digunakan dalam melakukan penerapan data karyawan sehingga diketahui struktur pohon penilaian karyawan hingga memprediksi pola karyawan yang ada. Terdapat data yang digunkana untuk mengolah data dan melakukan evaluasi data karyawan. Hasil dari pengolahan dievaluasi dengan konsep confusion matrix. Dengan metode algoritma $\mathbf{C 4 5}$, tingkat akurasi diperoleh sangat tinggi yakni $97,71 \%$. Kajian dilakukan pada restoran cepat saji di kota bogor dengan melihat jumlah karyawan yang besar sesuai dengan komposisi data mining.
\end{abstract}

Kata kunci-Algoritma C45, Data mining, Restoran Cepat Saji, Karyawan

\section{PENDAhUluan}

Restoran cepat saji merupakan objek kajian, khsusnya karyawan didalamnya. Hal ini dikarenakan pentingnya menjaga karyawan pada restoran cepat saji salah satunya dengan tujuan untuk menjaga kualitas penyajian dan pelayanan demi keberlangsungan nya dalam bisnis perusahaan. Pekerjaan yang paling padat dimana hampir tidak bisa duduk atau beristirahat sejenak terjadi pada restoran cepat saji, dengan bgitu tingkat kepadatan, tingkat kejenuhan sangat tinggi. Atas dasar ini maka perlunya menjaga salah satu aset dari perusahaan diluar dari aset tetap seperti bangunan dan tanah yakni karyawan. Pentingnya penghargaan pada karyawan restoran cepat saji merupakan salah satu apresiasi perusahaan untuk menjaga keberlangsungan usahanya.

Kajian terdahulu yang relevan dan sejenis terhadap restoran cepat saji yakni kajian mengenai kepuasan pelanggan pada restoran cepat saji yang lebih fokus membahas mengenai kepuasan konsumen dalam santap pada menu restoran cepat saji[1]. Kajian lain yang sejenis yakni kejian kepuasan konsumen terhadap restoran cepat saji dengan poendekatan data mining, menggunakan metode decicion tree[2]. Kajian yang dilakukan dalam naskah ini lebih pada sudut pandang yang berbeda dari segi penentuan karyawan terbaik, sebagai apresiasi terhadap karyawan dalam melakukan tugasnya.

Tujuan kajian yakni untuk menerapkan algoritma C45 dalam data restoran cepat saji, dengan demikian dilakukan pengembangan untuk terus meningkatkan akurasi, agar dapat di prediksi sesuai hasil akhir bahwa penerapan algorima C45 dengan konsep data mining dapat menentukan dengan akurat prediksi karyawan baik, kurang baik dan sangat baik.

\section{METODE}

\section{A. Data Mining}

Kajian ini menggunakan konsep data mining, data mining atau menggali data diartikan sebagai metode yang pakai untuk mengekstraksi informasi prediktif tersembunyi pada database, ini adalah pengetahuan yang sangat berguna bagi perusahaan dalam memberdayakan data warehouse nya[3]. Data mining disebut sebagai proses ekstraksi pengertahuan dari data yang besar, sesuai fungsinya data mining adalah proses pengambilan keputusan dari volume data yang besar yang disimpan dalam basis data, data warehouse, atau informasi yang disimpan dalam repository[4]. Istilah data mining berasal dari kemiripan antara pencarian informasi yang bernilai dari basis data yang besar dengan menambang sebuah gunung untuk memperoleh sesuatu yang bernilai[5]. Nilai baru nantikan akan dapat digunakan kembali dan diimplementasikan pada lingkungan baru yang sejenis, dengan bgitu terbentuk rule dari pola yang sudah ada pada restoran cepat saji. Pola baru ini merupakan habit atau kebiasaan dalam perusahaan tertentu dalam melakukan kajian terhadap pegawainya khsusnya penilaian karyawan terbaik

Kajian ini menggunakan desain dengan konsep CRISP-DM (Cross Standart Industries for Data Mining), yakni terdiri dari Business/Research Understanding Phase, Data Understanding Phase (Fase Pemahaman Data), Data Preparation Phase (Fase Pengolahan Data), Modeling Phase (Fase Pemodelan), Evaluation Phase (Fase Evaluasi), Deployment Phase (Fase Penyebaran) dalam metode ini terdapat 6 tahapan[6][7]: 


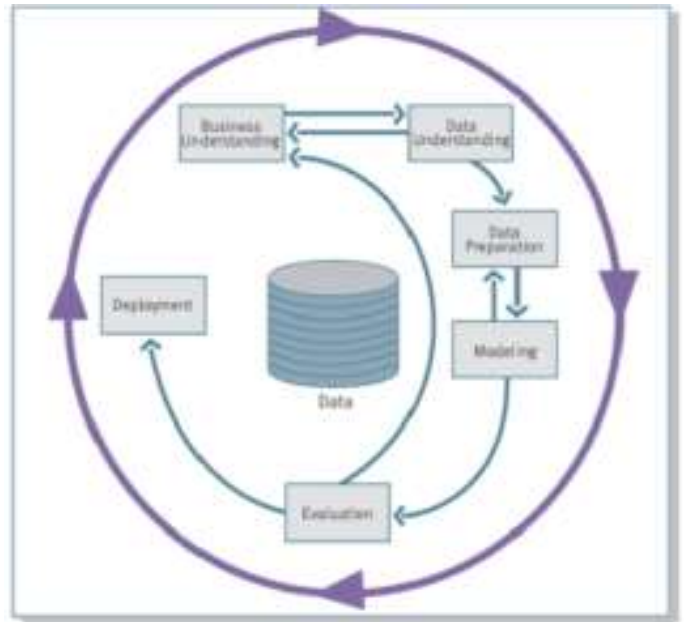

Gambar 1. Tahap CRISP-DM (Cross Standart Industries for Data Mining)

Dari tahapan tersebut diatas jika diterjemahkan maka Business/ Research Understanding Phase Dalam hal ini dilakukan pemahaman terhadap penelitian yang dilakukan perlunya pemhaman terhadap subtansi atau inti dari penelitian yang dilakukan mulai dari kebutuhan dan perspektif bisnis yang dilakukan, terdapat beberapa kegiatan pada tahapan ini diantaranya adalah ditentukannya sasaran dan tujuan dari penelitian, pemahaman kondisi atau situasi bisnis, menentukan tujuan dari data mining dan melakukan penjadwalan atau perencanaan strategi penelitian.

Data Understanding Phase (Fase Pemahaman Data). Dikenal dengan fase pemahaman terhadap data yang diperoleh kemudian data awal yang dikumpulkan perlu dilakukan kajian sehingga diketahui data yang akan digunakan. Dalam tahapan ini perlunya identifikasi terhadap masalah kualitas data yang baik sehingga diperoleh nilai subset yang sesuai, menarik dalam pembuatan hipotesa awal.

Data Preparation Phase (Fase Pengolahan Data). Tahapan ini meruapak tahapan pengolahan data atau dapat juga dikatakan sebagai tahapan persiapan data. Banyak persiapan yang dilakukan pada tahapan ini tak jarang fase ini juga disebut sebagai fase padat karya. Beberapa kegiatan seperti pemilihan tabel dan field terjadi pada fase ini. Pemilihan tabel dan field tersebut akan di masukan atau di transformasikan kedalam database yang lain atau database baru sebagai bahan atau data mentah, data mining mentah.

Modeling Phase (Fase Pemodelan). Pada fase pemodelan dilakukan penggunaan aplikasi seperti Rapidminer, aplikasi pengolah data mining mentah, dimasukan juga algoritma C4.5, dari data tersebut dipilih attribute yang menjadi label, seluruh parameter dipilih dengan penentuan nilai yang optimal.

Evaluation Phase (Fase Evaluasi). Fase ini merupakan tahapan analisa dari hasil pengolahan fase sebelumnya dengan meninterpretasikan data yang kemudian diperoleh nilai perbandingan dengan proses model yang sebelumnya. Perlunya kajian mendalam pada tahapan ini untuk menentukan nilai akurasi data model yang dihasilkan hal tersebut bertujuan agar dapat digunakan oleh sasaran sesuai rencana pada domain goal pada fase pertama
Deployment Phase (Fase Penyebaran). Fase ini merupakan tahapan pembuatan laporan atau implementasi knowledge yang diperoleh pada fase sebelumnya.

\section{B. Algoritma $\mathrm{C} 45$}

Algoritma C4.5 merupakan algoritma pengklasifikasi dengan teknik pohon keputusan yang terkenal dan disukai karena memiliki kelebihan-kelebihan. Kelebihan ini misalnya dapat mengolah data numerik (kontinyu) dan diskret, dapat menangani nilai atribut yang hilang, menghasilkan aturanaturan yang mudah diintrepetasikan dan tercepat diantara algoritma-algoritma yang lain. Keakuratan prediksi yaitu kemampuan model untuk dapat memprediksi label kelas terhadap data baru atau yang belum diketahui sebelumnya dengan baik. Dalam hal kecepatan atau efisiensi waktu komputasi yang diperlukan untuk membuat dan menggunakan model. Kemampuan model untuk memprediksi dengan benar walaupun data ada nilai dari atribut yang hilang. Dan juga skalabilitas yaitu kemampuan untuk membangun model secara efisien untuk data berjumlah besar (aspek ini akan mendapatkan penekanan). Terakhir interpretabilitas yaitu model yang dihasilkan mudah dipahami. Selain itu dapat juga dikatakan bahwa Algoritma merupakan kumpulan perintah yang tertulis secara sistematis guna menyelesaikan permasalahan logika dari matematika. Pengertian algoritma C4.5 merupakan algoritma yang digunakan untuk membentuk pohon keputusan. Sedang pohon keputusan dapat diartikan suatu cara untuk memprediksi atau mengklarifikasi yang sangat kuat. Pohon keputusan dapat membagi kumpulan data yang besar menjadi himpunan-himpunan record yang lebih kecil dengan menerapkan serangkaian aturan keputusan

Ada beberapa tahap dalam membuat sebuah pohon keputusan dengan algoritma $\mathrm{C} 4.5[8]$ :

1. Menyiapkan data training. Data training biasanya diambil dari data histori yang pernah terjadi sebelumnya dan sudah dikelompokkan ke dalam kelas-kelas tertentu.

2. Menentukan akar dari pohon. Akar akan diambil dari atribut yang terpilih, dengan cara menghitung nilai gain dari masing-masing atribut, nilai gain yang paling tinggi yang akan menjadi akar pertama. Sebelum menghitung nilai gain dari atribut, hitung dahulu nilai entropy. Untuk menghitung nilai entropy digunakan rumus:

$$
\operatorname{Entropy}(S)=\sum_{i=1}^{n}-p i \cdot \log _{2} p i
$$

Keterangan:

$\mathrm{S}$ = himpunan kasus

$\mathrm{n}=$ jumlah partisi $\mathrm{S}$

$\mathrm{p}_{\mathrm{i}}=$ proporsi $\mathrm{S}_{\mathrm{i}}$ terhadap $\mathrm{S}$

3. Kemudian hitung nilai gain menggunakan rumus:

$\operatorname{Gain}(S, A)=\operatorname{Entropy}(S)-\sum_{i=1}^{n} \frac{\|s i\|}{\|s\|} * \operatorname{Entropy}(S i)$ 
Keterangan:

$$
\begin{aligned}
& \mathrm{S}=\text { himpunan kasus } \\
& \mathrm{A} \quad \text { = fitur } \\
& \mathrm{n} \quad=\text { jumlah partisi atribut } \mathrm{A} \\
& \left|\mathrm{S}_{\mathrm{i}}\right|=\text { proporsi } \mathrm{S}_{\mathrm{i}} \text { terhadap } \mathrm{S} \\
& |\mathrm{S}|=\text { jumlah kasus dalam } \mathrm{S}
\end{aligned}
$$

4. Ulangi langkah ke-2 hingga semua record terpartisi.

5. Proses partisi pohon keputusan akan berhenti saat :

a. Semua record dalam simpul $\mathrm{N}$ mendapat kelas yang sama.

b. Tidak ada atribut di dalam record yang dipartisi lagi.

c. Tidak ada record di dalam cabang yang kosong.

Evaluasi menggunakan confusion matrix dengan rumusan sebagai berikut[9]:

TABEL 1. TABEL CONFUSION MATRIX

\begin{tabular}{ccc}
\hline \multirow{2}{*}{$\begin{array}{c}\text { Klasifikasi yang } \\
\text { benar }\end{array}$} & \multicolumn{2}{c}{ Diklasifikasikan sebagai } \\
\cline { 2 - 3 } & + & - \\
\hline+ & true positives & false negatives \\
- & false positives & true negatives \\
\hline
\end{tabular}

\section{HASIL DAN DISKUSI}

Kajian dilakukan dengan menggunakan perangkat lunak rapid miner 5.1. dengan menampilkan attribut sebagai berikut:

TABEL 2. ATTRIBUT DATA

\begin{tabular}{|l|l|c|}
\hline \multicolumn{1}{|c|}{ Role } & \multicolumn{1}{|c|}{ Nama Attribut } & Tipe \\
\hline Label & Jam Kerja & Polynomial \\
\hline Regular & Kreatifitas & Polynomial \\
\hline Regular & Disiplin & Polynomial \\
\hline Regular & Bermasalah & Polynomial \\
\hline Regular & Prestasi & Polynomial \\
\hline Regular & Etika & Polynomial \\
\hline Regular & Tanggung Jawab & Binomial \\
\hline Regular & Kepemimpinan & Polynomial \\
\hline Regular & Inisiatif & Polynomial \\
\hline Regular & Kerjasama & Polynomial \\
\hline Regular & Kebersihan & Binomial \\
\hline
\end{tabular}

Dari role attribut tersebut dilakukan pengolahan data sebanyak 437 record pada Rapidminer dengan pola sebagai berikut:

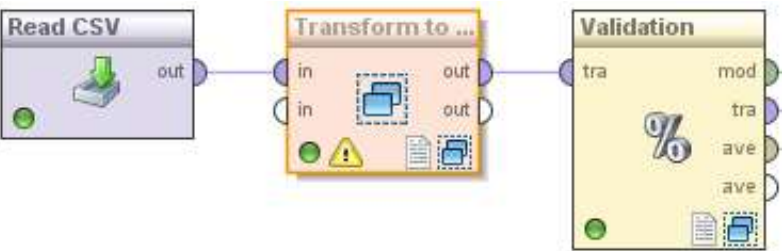

Gambar 1. Pola Pengolahan dengan Rapidminer (Main Proces)

Gambar 1. Menunjukan proses pembacaan terhadap data dengan format csv kemudian mengubah data menjadi nominal, polynomial atau binomial dan melakukan validasi untuk mengukur nilai akurasi nya. Penerapan algoritma C45 akan dilakukan pada proses validasi, proses akurasi juga dilakukan dalam tahapan validasi yang lebih sepsifik lagi seperti pada gambar 2 berikut ini:

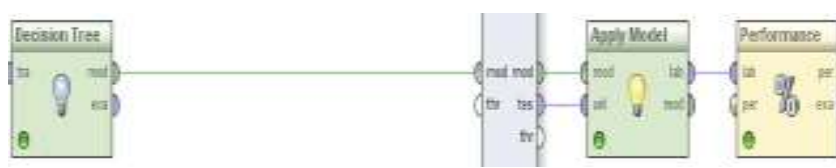

Gambar 2. Proses dengan Algoritma C45 dan Pengukuran Tingkat Akurasi

Seluruh proses dilakukan dengan tahapan CRIP-DM sehingga inputan dengan algoritma C45 kemudian dilakukan evaluasi menghasilkan memberikan hasil sebagai berikut:

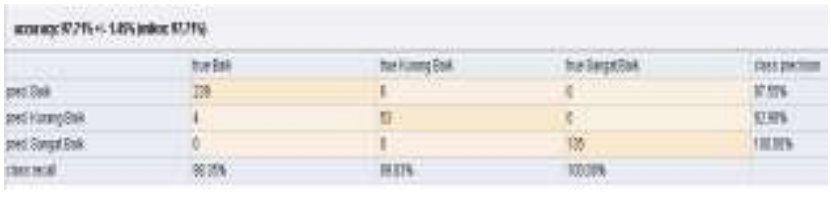

Gambar 3. Hasil Akurasi

Hasil pengukuran akurasi data diperoleh bahwa secara keseluruhan nilainya mencapai $97,71 \%$ dari tabel tersebut diketahui prediksi Baik, karyawan dengan true Baik mencapai nilai 239 karyawan dan untuk true Kurang Baik sebanyak 6 Karyawan dan true Sangat Baik sebanyak 0 Karyawan dengan hasil capaian nilai presisi mencapai sebesar $97.55 \%$ sedangkan untuk Prediksi Kurang Baik data karyawan untuk true Baik mencapai nilai 4 konsumen, untuk true Kurang Baik terdapat 53 Karyawan dan True Sangat Baik Sebanyak 0 Karyawan, persentase prediksi kurang baik adalah sebesar 92,98\% Karyawan untuk class Presisinya. Pada Prediksi Sangat Baik Nilai True Baiknya jumlahnya 0 karyawan, jumlah true kurang baik nya adalah 0 karyawan, dan prediksi sangat baik untuk true sangat baik mencapai 135 karyawan, dan ini merupakan jumlah karyawan teladan dengan class presisi mencapai sempurna $100 \%$. Untuk class recall data karyawan sangat tinggi yakni untuk class recall true baik mencapai $98.35 \%$, untuk class recall pada jumlah karyawan true kurang baik persentasenya mencapai $89,83 \%$, sedangkan untuk class recall true sangat baik mencapai nilai sempurna yakni $100 \%$ karyawan terbaik . Pengukuran akurasi melihat data lebih besar kepada karyawan sangat baik dengan tingkat akurasi tertinggi yang berbanding lurus dengan pengukuran presicion.

Dari hasil pada gambar 3 maka dilakukan pengukuran performance Vektor sebagai berikut: 
PerformanceVector:

accuracy: $97.71 \%+/-1.45 \%$ (mikro: $97.71 \%$

ConfusionMatrix:

True: Baik Kurang Baik Sangat Baik

Baik: 239

Kurang Baik: $4 \quad 53 \quad 0$

Sangat Baik: $0 \quad 0 \quad 135$

kappa: $0.960+/-0.026$ (mikro: 0.960)
ConfusionMatrix:

True: Baik Kurang Baik Sangat Baik

Baik: $239 \quad 6 \quad 0$

Kurang Baik: $4 \quad 53 \quad 0$

Sangat Baik: $0 \quad 0 \quad 135$

Berdasarkan algoritma C45 juga dapat memberikan gambaran pohon keputusan yang disusun berdasarkan nilai entropy dan nilai Gain, memberikan klasifikasi penggolongan berdasarkan pohon atau simpul, cabang hingga membuat leaf, sebagai berikut:

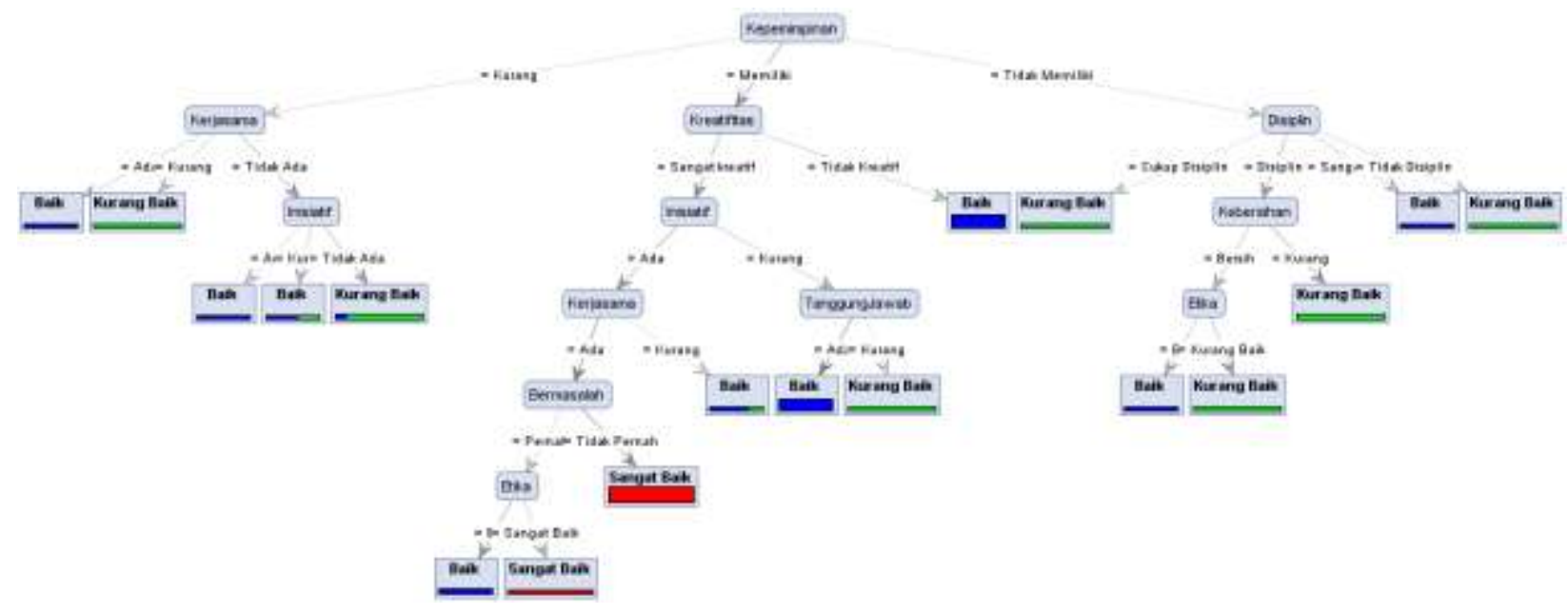

Gambar 4. Pohon Penilaian Karyawan Pada Restoran Cepat Saji

Dari gambar 4 dapat disederhanakan dalam bentuk teks yang dapat lebih difahami dengan baik, dengan menjabarkan sebagai berikut:

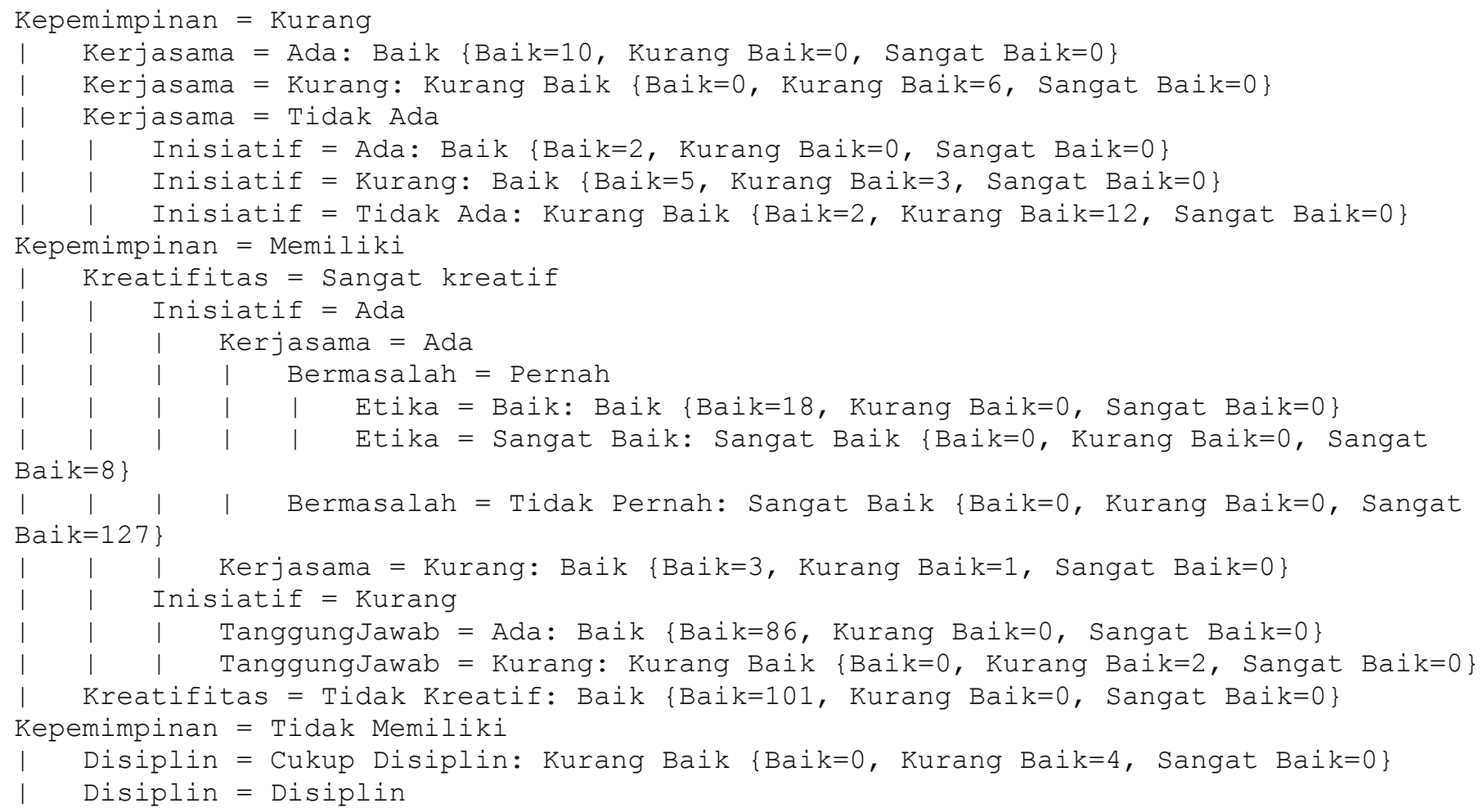




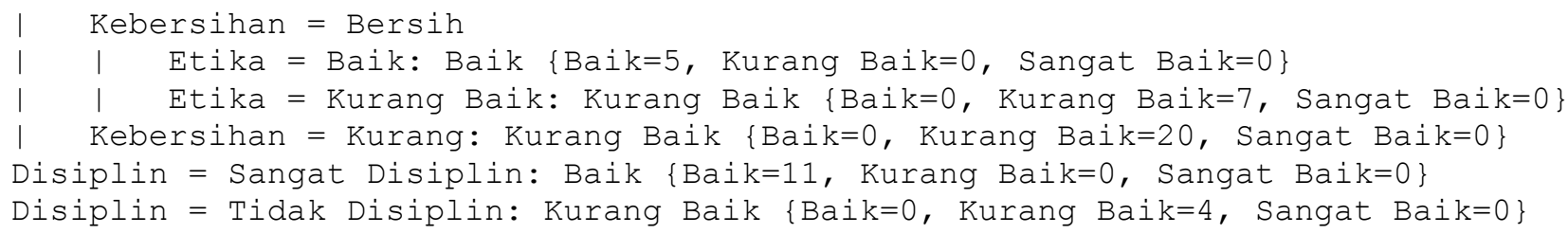

Sehingga dapat diketahui setiap cabang dan setiap leaf nya memiliki nilai dan jumlah karyawan yang baik, kurang baik dan jumlah karyawan sangat baik dari penjabaran gambar 4 maka dapat disebut sebagai rule baru atau model baru yang ditemukan untuk menyelesaikan model lain.

Berdasarkan gambar 3 dan gambar 4 maka dapat dibuat penggolongan pengukuran tingkat akurasi yang dapat dibagi menjadi beberapa kelompok[10]:

a. $0.90-1.00=$ klasifikasi sangat baik

b. $0.80-0.90=$ klasifikasi baik

c. $0.70-0.80=$ klasifikasi cukup

d. $0.60-0.70=$ klasifikasi buruk

e. $0.50-0.60=$ klasifikasi salah

Dari nilai hasil pengukuran akurasi maka dapat disimpulkan sesuai dengan pengelompokan klasifikasi masuk pada klasifikasi sangat baik untuk Penerapan algoritma C45 pada karyawan restoran cepat saji.

\section{KeSIMPULAN}

Penerapan algoritma C45 pada karyawan restoran cepat saji memiliki tingkat akurasi yang termasuk dalam klasifikasi sangat baik yakni $97,71 \%$ atau sekitar 135 karyawan dengan class presisi dan prediksi mencapai $100 \%$, sedangkan yang baik sebanyak 239 karyawan presisinya sebesar $97 \%$, karywan yang kurang baik berjumlah 53 karyawan dengan presisi $92 \%$. Kategori penelitian ini masuk dalam klasifikasi sangat baik dengan persentase $0.90-1.00$.

Dengan tingkat akurasi yang sangat baik maka penilaian karyawan pada restoran cepat saji dapat dilakukan dengan rule yang telah dihasilkan menggunakan algoritma C45. Kedepannya rule tersebut dapat dijadikan model dalam pengembangan perangkat lunak untuk kepentingan restoran cepat saji.
Dari hasil tersebut maka perlu terus dikembakan dan dikomparasikan dengan beberapa algoritma lain dan beberapa metode lain seperti SEMMA dan KDD sehingga hasil akurasi bisa jauh lebih sempurna lagi.

\section{DAFTAR PUSTAKA}

[1] H. Dhika, F. Destiawati, and A. Fitriansyah, "Implementasi Algoritma C4.5 Terhadap Kepuasan Pelanggan,” SNAPP 2016, vol. Vol. 6, no. Sains dan Teknologi, pp. 16-22, 2016.

[2] V. Mandasari, B. A. Tama, and U. Sriwijaya, “Analisis Kepuasan Konsumen Terhadap Restoran Cepat Saji Melalui Pendekatan Data Mining : Studi Kasus XYZ,” J. Generik, vol. 6, no. 1, pp. 4-7, 2011.

[3] M. K. A. J. P. Jiawei Han, "Data Mining: Concepts and Techniques, Third Edition - Books24x7," Morgan Kaufmann Publishers, 2012. .

[4] J. J. . Han, M. M. . Kamber, and J. Pei, Data Mining: Concepts and Techniques. 2012.

[5] S. Sumathi and S. N. Sivanandam, "Data warehousing, data mining, and OLAP,” Stud. Comput. Intell., vol. 29, pp. 21-73, 2007.

[6] C. McGregor, C. Catley, and A. James, "A process mining driven framework for clinical guideline improvement in critical care," in CEUR Workshop Proceedings, 2011, vol. 765.

[7] A. Azevedo and M. F. Santos, "KDD, SEMMA and CRISP-DM: a parallel overview," IADIS Eur. Conf. Data Min., no. January, pp. 182-185, 2008.

[8] S. Goswami, S. Chakraborty, S. Ghosh, A. Chakrabarti, and B. Chakraborty, "A review on application of data mining techniques to combat natural disasters," Ain Shams Eng. J., 2016.

[9] M. Bramer, Principles of Data Mining. 2007.

[10] F. Gorunescu, "Data mining: Concepts, models and techniques," Intell. Syst. Ref. Libr., vol. 12, 2011. 